\title{
Middle-school students' school lunch consumption does not meet the new Institute of Medicine's National School Lunch Program recommendations
}

\author{
Karen W Cullen*, Kathleen B Watson and Jayna M Dave \\ Department of Pediatrics, USDA/ARS Children's Nutrition Research Center, Baylor College of Medicine, \\ 1100 Bates Street, Houston, TX 77030-2600, USA
}

Submitted 16 July 2010: Accepted 14 February 2011: First published online 19 April 2011

\begin{abstract}
Objective: To compare the school lunch consumption of Texas middle-school students with the 2009 Institute of Medicine's (IOM) school meal report recommendations. These new lunch menu patterns increase fruit to one serving and vegetables to two servings, with $50 \%$ wholegrain food.

Design: Lunch food records were collected from middle-school students from four schools in south-east Texas in the spring of 2008, and entered into the Nutrition Data System for Research software. Average intake was calculated for those consuming meals according to the National School Lunch Program (NSLP; $n$ 5414) and for those consuming lunch from other sources ( $n$ 239). The percentage of students selecting each food group was calculated.

Setting: Middle schools in south-east Texas.

Subjects: Middle-school students in south-east Texas.

Results: Students consuming NSLP meals reported consuming almost $\frac{1}{2}$ serving of fruit, $\frac{3}{4}$ serving of vegetables, $8 \mathrm{oz}$ of milk and $\frac{1}{3}$ serving of whole grains at lunch. Non-NSLP consumers reported almost no intake of fruit, vegetables or milk, and consumed $\frac{1}{4}$ serving of whole grains at lunch. Among NSLP consumers, about $40 \%$ selected and consumed a fruit serving. About two-thirds of students selected a vegetable, consuming about $67 \%$. Less than $4 \%$ selected a dark green or orange vegetable. Conclusions: Students' lunch intake did not meet the new IOM recommendations. Few students selected dark green or orange vegetables, and only $40 \%$ selected fruit. Whole grains consumption was low. Interventions with all stakeholders will be necessary to improve students' food and beverage selections overall when school meal patterns are revised.
\end{abstract}

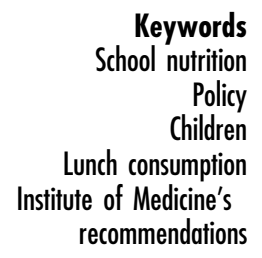

The White House Task Force on Childhood Obesity identified the provision of healthy food in schools as one of the four priority areas in their 2010 report Solving the Problem of Childhood Obesity Within a Generation ${ }^{(1)}$. In the fiscal year 2009, US schools served about 31 million lunches $^{(2)}$ and 11 million breakfasts each day through the US Department of Agriculture's (USDA) school meal programmes $^{(3)}$. Approximately $60 \%$ of these meals were provided for free or at a reduced price ${ }^{(3)}$. The Task Force Report's first school recommendation ${ }^{(1)}$ urged the USDA to adopt the 2009 Institute of Medicine's (IOM) recommendations for new nutritional standards and meal requirements for the federal breakfast and lunch programmes $^{(4)}$. The school meal regulations have not been updated since $1995^{(5)}$. Currently, students can select one serving of fruit in a breakfast meal and a total of two servings of fruit and/or vegetables in a lunch meal. The use of wholegrain food is encouraged ${ }^{(6)}$. The USDA commissioned the IOM to provide new recommendations that align the federal meal programmes with the US Dietary Guidelines and Dietary Reference Intakes to ensure that the meals promote health and reduce inadequate and excessive intakes ${ }^{(4)}$.

The 2009 IOM report provides new meal requirements and a minimum and maximum amount of energy per meal for the first time ${ }^{(4)}$. Fruit in the breakfast meal pattern would double and students would be able to select two servings (one cup total). For lunch, students would be able to select two servings (one cup) of vegetables and one serving (half cup) of fruit, which would be one serving more than the current standard of a total of two servings of fruit and vegetables. Starchy vegetables would be limited, and there would be requirements to offer specific servings of dark green and orange vegetables and legumes each week ${ }^{(4)}$. Finally, $50 \%$ of grains would have to be rich in whole grains ${ }^{(4)}$. These added components 
should contribute to improve students' dietary intake at school, if selected and consumed ${ }^{(4)}$.

The current paper presents the results of a study that compared the lunch consumption of middle-school students in south-east Texas with the new recommendations specified in the IOM school meal report. Lunch consumption was examined among students who consumed at least one item from the National School Lunch Program (NSLP) meal and among those not consuming any NSLP food at lunch. The percentage of students selecting each food group and the mean consumption of those food groups were also assessed.

\section{Methods}

\section{Target population}

Students from four middle schools in one school district in south-east Texas participated in the present study in the spring of 2008. The schools were participating in a pilot study investigating methods to improve school breakfast participation and three were selected by the school food service director to have high rates of lowincome students. The schools were primarily Hispanic $(57 \%, 78 \%, 82 \%$ and $93 \%)$ and the rates of students who were eligible to receive free or reduced price meals were $51 \%, 77 \%, 84 \%$ and $85 \%$. Approximately $55 \%$ of Texas students were eligible for free or reduced price meals in $2008^{(7)}$. The school utilized the offer $v$. serve (OVS) provision, which allows students to select fewer meal components as long as the meal meets a specified minimum $^{(6)}$. The study was approved by the Institutional Review Board at Baylor College of Medicine.

\section{Procedures}

All parents received information about the study and were notified that their child could assent or refuse to complete anonymous lunch food records during lunch. Trained data collectors visited each school cafeteria $2-3 \mathrm{~d} /$ week. They selected one to two tables of students at each lunch period and asked students to complete the anonymous lunch food records after eating in order to maximize the self-report accuracy $^{(8)}$. No data were recorded on refusals. Students could have completed more than one lunch food record during the study period. Students were shown how to complete the record by listing the food items consumed on separate lines, as well as the amount and source of each food (school lunch, snack bar, home, vending and other source). This method of food record data collection was shown to be valid in previous research ${ }^{(9)}$.

\section{Data}

The weekly average servings of fruit, vegetables (by subgroup) and whole grains on the school menus were calculated. The district used a 6-week-cycle menu. The food records were entered into a nutrition calculation software program (Nutrition Data System for Research 2008; Nutrient Coordinating Center, University of Minnesota, MN, USA) to obtain consumption levels of nutrients (energy, protein, vitamins $\mathrm{A}$ and $\mathrm{C}, \mathrm{Ca}, \mathrm{Fe}$, total and saturated fat) and servings of the food groups from the IOM guidelines for school meal (fruit or juice, vegetables (total, dark green, orange or deep yellow), other vegetables (tomatoes and other vegetables), starchy vegetables (white potatoes, corn and peas), legumes, high-fat vegetables, whole grains, refined/some whole grains, and milk ${ }^{(10)}$. Na and fibre intakes were also calculated.

\section{Statistical analysis}

Descriptive statistics (e.g. frequency, mean and sD) were calculated. The average daily intake per person for all the nutrients and food groups identified above was calculated for the NSLP and non-NSLP groups. Wilcoxon's nonparametric one-sample tests were conducted against the standard USDA recommendations (the targeted level) for all listed nutrients and for servings of fruit or juice, vegetables and wholegrain foods for the NSLP consumers. Percentages were used to describe the proportion of students meeting or exceeding both the current guidelines and the new recommendations. Finally, the percentage of students selecting each food group and the amount consumed by those selecting the food were calculated.

\section{Results}

A total of 5653 lunch food records were collected. There were 5414 (95\%) records pertaining to students who reported consuming at least one item from the NSLP meal. Of the 239 (4\%) records pertaining to students who reported consuming no items from the NSLP meal, 37\% brought food from home, $54 \%$ purchased food from a snack bar, $2 \%$ received food from 'other sources', $6 \%$ brought food from home and also purchased food from the snack bar and $<1 \%$ purchased food from the snack bar and/or received food from 'other sources'.

A variety of fruit and vegetables were offered on the published school district menus. Two fruit choices were offered daily. Over a week, the following servings of vegetable subgroups were offered: two oranges, two starchy foods, one to two dark green vegetables, one legume and six other vegetables. French fries were offered only 2 times/week, as per the Texas Public School Nutrition Policy, which also provides guidelines for foods sold outside the NSLP meal ${ }^{(11)}$. An average of one serving of whole grains was offered per week.

Middle-school students who consumed NSLP meals reported higher lunch intakes of protein, $\mathrm{Ca}$, Fe, vitamins $\mathrm{A}$ and $\mathrm{C}$ and fibre compared with those who consumed non-NSLP meals (Table 1). However, for both the NSLP and non-NSLP groups, nutrient intakes were significantly different from the recommended levels, except for the 
Table 1 USDA and IOM NSLP guidelines, mean and SD of school lunch nutrient intake among students consuming $(n 5414)$ and not consuming ( $n$ 239) NSLP foods ${ }^{\star}$ and percentage of NSLPconsuming students meeting the NSLP and IOM guidelines, from lunch food records completed by students in the cafeteria

\begin{tabular}{|c|c|c|c|c|c|c|c|c|}
\hline \multirow[b]{2}{*}{ Nutrient } & \multicolumn{2}{|c|}{ Meal recommendations } & \multicolumn{4}{|c|}{ NSLP consumers } & \multicolumn{2}{|c|}{ Non-NSLP consumers } \\
\hline & USDA & IOM & Mean & SD & $\begin{array}{l}\text { Percentage meeting } \\
\text { USDA standard }\end{array}$ & $\begin{array}{l}\text { Percentage meeting } \\
\text { IOM standard }\end{array}$ & Mean & SD \\
\hline Energy (kJ) & $3452+$ & $2520-2940 \S$ & $2916 \cdot 0$ & $946 \cdot 0$ & $73 \cdot 0$ & $16 \cdot 8$ & $1485 \cdot 0$ & $874 \cdot 0$ \\
\hline$\%$ Energy from fat & $\leq 30$ & $25-35$ & $41 \cdot 4$ & $18 \cdot 4$ & $27 \cdot 6$ & $34 \cdot 8$ & $31 \cdot 1$ & $17 \cdot 2$ \\
\hline$\%$ Energy from saturated fat & $\leq 10$ & $\leq 10$ & $16 \cdot 3$ & $8 \cdot 4$ & $18 \cdot 8$ & $18 \cdot 8$ & $9 \cdot 7$ & $8 \cdot 1$ \\
\hline Total protein $(\mathrm{g})$ & $\geq 16$ & $\geq 32 \cdot 2$ & 32.9 & $14 \cdot 1$ & $90 \cdot 8$ & $51 \cdot 7$ & $9 \cdot 3$ & 11.5 \\
\hline $\mathrm{Ca}(\mathrm{mg})$ & $\geq 400$ & $\geq 440$ & $544 \cdot 0$ & $296 \cdot 0$ & $72 \cdot 5$ & $69 \cdot 0$ & $101 \cdot 0$ & $126 \cdot 0$ \\
\hline $\mathrm{Fe}(\mathrm{mg})$ & $\geq 4.5$ & $\geq 5.2$ & 3.9 & 1.5 & $32 \cdot 6$ & $16 \cdot 0$ & 1.9 & 1.6 \\
\hline Vitamin A (RE) & $\geq 300$ & $\geq 241$ & $257 \cdot 8$ & $344 \cdot 0$ & $30 \cdot 7$ & $55 \cdot 4$ & $45 \cdot 5$ & $62 \cdot 6$ \\
\hline Vitamin C (mg) & $\geq 18$ & $\geq 30$ & $17 \cdot 1$ & $18 \cdot 7$ & $28 \cdot 5$ & $13 \cdot 0$ & $8 \cdot 4$ & $26 \cdot 3$ \\
\hline Total dietary fibre (q) & - \pm & $\geq 8.6$ & $5 \cdot 1$ & 2.6 & - \pm & $9 \cdot 7$ & 1.8 & 1.7 \\
\hline $\mathrm{Na}(\mathrm{mg})$ & $\begin{array}{r}+ \\
-\ddagger\end{array}$ & $<704$ & $1155 \cdot 0$ & $540 \cdot 0$ & $\begin{array}{r}+ \\
-\ddagger\end{array}$ & $18 \cdot 0$ & $522 \cdot 0$ & $586 \cdot 0$ \\
\hline
\end{tabular}

USDA, US Department of Agriculture; IOM, Institute of Medicine; NSLP, National School Lunch Program; RE, retinol equivalent.

${ }^{*}$ All nutrients and servings for both NSLP and non-NSLP groups were significantly different at $P<0.005$ from the recommended levels, except for \%fat and \%SFA among non-NSLP consumers. $+825 \mathrm{kcal}$.

.

$\$ 600-700 \mathrm{kcal}$

Table 2 Amount consumed (svg or oz) for all students, percentage of students who selected the food and amount consumed for those who selected the food among students consuming NSLP $(n$ 5414) and not consuming NSLP ( $n$ 239) school lunch foods, from lunch food records completed by students in the cafeteria

\begin{tabular}{|c|c|c|c|c|c|c|c|c|c|c|}
\hline \multirow[b]{3}{*}{ Food } & \multicolumn{5}{|c|}{ NSLP consumers } & \multicolumn{5}{|c|}{ Non-NSLP consumers } \\
\hline & \multicolumn{2}{|c|}{$\begin{array}{c}\text { Amount } \\
\text { consumed: all }\end{array}$} & \multirow{2}{*}{$\begin{array}{c}\begin{array}{c}\text { Students who } \\
\text { selected }\end{array} \\
\%\end{array}$} & \multicolumn{2}{|c|}{$\begin{array}{l}\text { Amount consumed - } \\
\text { if selected }\end{array}$} & \multicolumn{2}{|c|}{$\begin{array}{c}\text { Amount } \\
\text { consumed: all }\end{array}$} & \multirow{2}{*}{$\begin{array}{c}\begin{array}{c}\text { Students who } \\
\text { selected }\end{array} \\
\%\end{array}$} & \multicolumn{2}{|c|}{$\begin{array}{l}\text { Amount consumed - } \\
\text { if selected }\end{array}$} \\
\hline & Mean & SD & & Mean & SD & Mean & SD & & Mean & SD \\
\hline Fruit/100\% juice (svg) & 0.43 & 0.61 & $40 \cdot 2$ & $1 \cdot 06$ & 0.50 & $0 \cdot 15$ & 0.49 & $11 \cdot 7$ & $1 \cdot 29$ & 0.77 \\
\hline Regular vegetables (svg) & $0 \cdot 72$ & 0.86 & $66 \cdot 9$ & 1.08 & 0.85 & 0.05 & 0.23 & $13 \cdot 0$ & 0.41 & 0.51 \\
\hline Dark green vegetables (svg) & 0.02 & 0.14 & $3 \cdot 6$ & 0.69 & 0.27 & 0.00 & 0.00 & $0 \cdot 0$ & 0.00 & 0.00 \\
\hline Orange/yellow vegetables (svg) & 0.02 & $0 \cdot 14$ & $3 \cdot 8$ & 0.43 & 0.56 & 0.00 & 0.00 & $0 \cdot 0$ & 0.00 & 0.00 \\
\hline Starchy vegetables (svg) & 0.39 & 0.70 & $47 \cdot 3$ & $0 \cdot 82$ & 0.83 & 0.03 & $0 \cdot 20$ & $4 \cdot 6$ & 0.59 & $0 \cdot 79$ \\
\hline Other vegetables (svg) & 0.29 & 0.51 & $53 \cdot 3$ & 0.55 & 0.59 & 0.03 & 0.08 & $12 \cdot 1$ & $0 \cdot 22$ & $0 \cdot 12$ \\
\hline Legumes (svg) & 0.02 & 0.14 & $2 \cdot 1$ & $0 \cdot 76$ & 0.58 & 0.00 & 0.06 & $0 \cdot 4$ & $1 \cdot 00$ & $\mathrm{~N} / \mathrm{A}$ \\
\hline High-fat (fried) vegetables (svg) & $0 \cdot 16$ & 0.37 & $14 \cdot 9$ & 1.04 & $0 \cdot 12$ & 0.01 & $0 \cdot 11$ & $0 \cdot 4$ & 1.63 & $\mathrm{~N} / \mathrm{A}$ \\
\hline Whole grains (svg) & $0 \cdot 35$ & 0.58 & $31 \cdot 0$ & $1 \cdot 12$ & 0.49 & $0 \cdot 24$ & 0.35 & 38.9 & 0.63 & $0 \cdot 27$ \\
\hline Refined/some whole grains (svg) & $1 \cdot 56$ & $1 \cdot 40$ & $79 \cdot 6$ & $1 \cdot 95$ & 1.29 & 0.97 & $1 \cdot 18$ & $63 \cdot 2$ & 1.54 & $1 \cdot 16$ \\
\hline All milk (oz) & $8 \cdot 18$ & $5 \cdot 85$ & $78 \cdot 7$ & $10 \cdot 39$ & 4.53 & 0.42 & $2 \cdot 31$ & $3 \cdot 8$ & $11 \cdot 28$ & $4 \cdot 51$ \\
\hline Whole/reduced-fat milk (oz) & $0 \cdot 36$ & $1 \cdot 27$ & $16 \cdot 9$ & $2 \cdot 11$ & $2 \cdot 41$ & 0.02 & 0.34 & $2 \cdot 1$ & $1 \cdot 17$ & $2 \cdot 32$ \\
\hline Low-fat/fat-free milk (oz) & $7 \cdot 82$ & $5 \cdot 53$ & $75 \cdot 6$ & $10 \cdot 35$ & $3 \cdot 78$ & 0.40 & $2 \cdot 16$ & $3 \cdot 3$ & $11 \cdot 07$ & 0.04 \\
\hline
\end{tabular}

svg, servings; NSLP, National School Lunch Program; N/A, not applicable. 
percentage of energy from fat and saturated fat in the nonNSLP group (Table 1). Less than one-third of students met the USDA-recommended nutrient intakes, with the exception of protein $(90 \cdot 8 \%)$ and $\mathrm{Ca}(72 \cdot 5 \%)$. Approximately $27 \%$ consumed more than the USDA energy recommendation and $50 \%$ of the students exceeded the new IOM energy recommendation (data not shown). Compared with the results for students meeting the current USDA guidelines, fewer students met the IOM recommendations for fat, protein, $\mathrm{Ca}, \mathrm{Fe}$ and vitamin $\mathrm{C}$ and more met the vitamin $\mathrm{A}$ value. Very few students met the IOM recommendations for fibre $(9 \cdot 7 \%)$ and $\mathrm{Na}(18 \cdot 0 \%$; Table 1$)$. Na intake was high among students consuming NSLP meals: $1155 \mathrm{mg}$ compared with the IOM target of $740 \mathrm{mg}$.

Among the NSLP consumers, 19\% met the current recommendations for total consumption of fruit or juice and vegetables (two servings) and 16\% consumed half of their grains in the form of wholegrain food (data not shown). When compared with the IOM recommendations, $28.5 \%$ consumed one serving of fruit or juice but only $10 \%$ consumed two servings of vegetables (data not shown). Overall, NSLP consumers reported intakes of almost $\frac{1}{2}$ serving of fruit, $\frac{3}{4}$ serving of vegetables, $8 \mathrm{oz}$ of milk (96\% low fat or skimmed) and $\frac{1}{3}$ serving of whole grains at lunch (Table 2). Non-NSLP consumers reported almost no fruit, vegetables or milk at lunch.

Among those consuming NSLP meals, about $40 \%$ of students selected a fruit and the entire fruit was consumed (Table 2). Whereas almost two-thirds of students selected a vegetable and $67 \%$ of the serving was eaten, $<4 \%$ selected a dark green or orange vegetable and only $2 \%$ selected a legume. Consumption among NLSP consumers was less than half for orange vegetables (43\%) but higher for dark green vegetables (69\%) and legumes (76\%). Approximately half of the students selected a starchy vegetable and consumed $82 \%$ of the serving, whereas nearly $53 \%$ selected other vegetables and consumed almost half of the serving. High-fat, fried vegetables were selected by only $15 \%$ of students; however, the entire serving was consumed. Whole grains were selected by about $31 \%$ of students and the entire serving was consumed. Approximately $79 \%$ of students selected milk and consumed $10 \mathrm{oz}$, on average. Milk was available in a $11 \mathrm{oz}$ container and most milk selections were low fat/fat free.

Only about $13 \%$ of the non-NSLP meal consumers selected a vegetable; 39\% selected whole grains and 63\% selected refined grains (Table 2). Less than $\frac{2}{3}$ serving of whole grains was consumed, compared with about 1.5 servings of refined grains.

\section{Discussion}

Increasing the number of servings of fruit, vegetables and whole grains in the federal school meal patterns to meet the recommendations in the dietary guidelines may not translate into improved dietary intake for students. The results from the present study show that, with the current guidelines, few middle-school students selected legumes, dark green or orange vegetables $(<4 \%)$ when they were on the menu. Only $40 \%$ selected fruit at lunch. The good news is that all of the fruit and much of the vegetables (43-100\%) were consumed by those who selected them, endorsing previous research indicating that children have higher preferences for fruit than for vegetables ${ }^{(12)}$. However, when compared with the new IOM recommendations, about one-quarter consumed one serving of fruit or juice but only $10 \%$ consumed two servings of vegetables.

The percentage of students in the present study who consumed fruit or juice was somewhat higher than the percentage in a national study conducted during the 2004-2005 school year $(40 \cdot 2 \% v \cdot 26 \cdot 0 \%)$, as were the proportions who consumed vegetables $(66 \cdot 9 \% v .45 \cdot 0 \%)$ and milk $(78.7 \% v \cdot 65 \cdot 0 \%)^{(13)}$. Smaller proportions of students in the present study reported consuming high-fat vegetables compared with those in the national study $(14 \cdot 9 \% v \cdot 24 \cdot 0 \%)^{(13)}$. The percentage of students selecting dark green and orange vegetables was similar $(\sim 4 \%)$. No data on food group consumption were published in the national study. In a Texas study, middle-school students reported lunch consumption of 0.89 serving of total vegetables (excluding high-fat vegetables), 0.45 serving of fruit or juice and $6.5 \mathrm{oz}$ of milk in the 2005-2006 school year ${ }^{(14)}$. Results from a national study indicated that about $29 \%$ of school lunch menus offered a green or orange vegetable other than potatoes, but $<6 \%$ of students consumed them. In all, $50 \%$ of the students were offered fresh fruit, but only $16 \%$ of NSLP participants consumed fresh fruit, and only $20 \%$ consumed a canned fruit on those days ${ }^{(14)}$.

The OVS provision is mandatory for secondary schools and optional for lower grades and may influence students' lunch intakes ${ }^{(6)}$. Although there is limited research on the OVS provision, an Alabama elementary-school study found that $2-46 \%$ of students selected vegetables during a week, whereas $4-53 \%$ selected a fruit ${ }^{(14)}$. Unfortunately, vegetable consumption is less than optimal even without OVS. Fourth grade students in Georgia who did not have a choice and were served the fruit and vegetables identified in the menu pattern consumed $84 \%$ of the fruit but only $51 \%$ of the vegetables ${ }^{(17)}$. Methods to improve fruit and vegetable preferences and selection in school cafeterias are needed.

Students consumed few whole grains at school ${ }^{(15,16)}$. National data also revealed low wholegrain food intake. The mean wholegrain food intake of 9-13-year-old children in the 1999-2002 National Health and Nutrition Examination Survey (NHANES) was $0.6 \mathrm{oz}$ equivalent serving, which is $20 \%$ of the recommendation ${ }^{(4)}$ but $>0.35 \mathrm{oz}$ equivalent serving was reported in the present study. The calculation of whole grains may be responsible for this difference, as the nutrition calculation 
software used in the present study also produces a variable called refined or some whole grains, whereas the NHANES analysis uses the MyPyramid food equivalent database and captures all whole grains ${ }^{(4)}$. However, although wholegrain foods were selected by only $31 \%$ of students, over $1 \mathrm{oz}$ equivalent serving was consumed by those who selected them. Wholegrain foods were on the menu only about 1 time/week. There are some wholegrain products available for use in school food service operations; however, the higher cost of wholegrain foods is an issue ${ }^{(4)}$, as is the acceptability by students ${ }^{(18)}$. A few studies suggest that inclusion of wholegrain foods in school lunches may be well received by children, but acceptance of $100 \%$ wholegrain foods is lower than acceptance of $50 \%$ wholegrain products ${ }^{(19,20)}$. In a previous focus group study identifying ways to promote new foods in the cafeteria, children reported that 'new foods would be accepted if they looked and tasted good and were familiar' and 'could be promoted through sampling, peer influence and providing incentives ${ }^{(18)}$. Adults who were directly asked how to increase wholegrain food in school meals identified the need for nutritional education and a gradual increase in wholegrain foods in school menus ${ }^{(18)}$. Increasing the number of affordable and acceptable wholegrain food products in the market place will depend on collaboration with the food industry.

$\mathrm{Na}$ deserves special attention, as high $\mathrm{Na}$ intake is a significant problem for students, as found in the present study, as well as for most adults ${ }^{(21)}$, and efforts to reduce $\mathrm{Na}$ intake have met with limited success. A 2010 IOM report recommended setting mandatory national standards for the $\mathrm{Na}$ content in foods that reduce the excess $\mathrm{Na}$ content in processed foods as a primary new strategy to reduce $\mathrm{Na}$ intake $^{(21)}$. Most $\mathrm{Na}(75 \%)$ in school meals was from processed foods; the largest Na sources were combination entrees (43\%) and accompaniments $(17 \%)^{(22)}$. Although drastic reductions in $\mathrm{Na}$ content in foods might cause reduced student participation, small and gradual reductions in $\mathrm{Na}$ content should maintain students' acceptability and participation ${ }^{(23)}$. New products and recipes that are lower in $\mathrm{Na}$ content, which are acceptable to students, are needed. The food industry will need to be a partner in this process to reduce the $\mathrm{Na}$ level in processed foods.

A recent report compared students' lunch intake collected in 2006 with the new IOM recommendations ${ }^{(24)}$. Among 11-13-year-old students in that study, only $18 \cdot 0 \%, 61 \cdot 0 \%$ and $29.9 \%$ met the new IOM recommendations for energy and percentage of energy intake from fat and saturated fat, respectively, compared with $16 \cdot 8 \%, 34 \cdot 8 \%$ and $18.8 \%$ in the present study. Whether the school observed the OVS policy or whether there were state guidelines for foods offered outside the NSLP was not stated and could account for the differences between the two studies.

The results from the present study identified the need for nutritional education and marketing efforts. For example, previous research documented that elementary-school students did not select more fruit or vegetables when a salad bar was introduced ${ }^{(25)}$. However, after students received six nutritional classes, more fresh fruit and salad bar items were selected when compared with schools with only a salad bar. The involvement and support of the school community and parents are also critical for success. Promising strategies to promote consumption of new foods include taste testing for parents and students ${ }^{(26-28)}$, signs on the food line $e^{(26,28)}$, parent meetings ${ }^{(23)}$ and media campaigns ${ }^{(26,28))}$.

The IOM report also recommended training on the new meal patterns for school food service staff for successful implementation. This could include marketing and presentation tips, as well as training for the food service staff to offer positive encouragement about the foods during meal service $e^{(29-31)}$.

There are several limitations that should be noted. The entire student data were self-reported, which is limited by memory and ability to estimate portion size ${ }^{(32)}$. No comparison between those who did and did not complete food records could be calculated. Students could have provided multiple assessments; to minimize this bias the data were aggregated by week. The study was conducted in four schools in the Houston area, with primarily Hispanic students, limiting generalizability. There could also be bias associated with social clustering at lunch tables, or the possible clustering effect of schools.

The key finding from the present study is that middleschool students' lunch consumption at school does not meet the recommendations for fruit, vegetables and whole grains proposed in the 2009 IOM school meals report ${ }^{(4)}$. Once the legislation with the revised nutritional standards and meal requirements has been approved, it will be critical that the recommendation for technical support and monitoring, evaluation and research be implemented. Intervention with all the stakeholders will be necessary so that appropriate support is provided to improve students' food and beverage selections when school meal patterns are revised.

\section{Acknowledgements}

The present study was funded by the National Institutes of Health (R21HD51661-2). It was also funded in part by federal funds from the US Department of Agriculture (USDA)/Agricultural Research Service under Cooperative Agreement no. 58-6250-6001. The contents of this publication do not necessarily reflect the views or policies of the USDA, nor does mention of trade names, commercial products, or organizations imply endorsement by the US Government. The authors have no conflict of interest to declare. K.W.C conceptualized the study, oversaw implementation and wrote the paper; K.B.W. conducted the data analyses and participated in manuscript preparation; J.M.D. participated in manuscript preparation. We are grateful to the participating schools and students. 


\section{References}

1. Task Force on Childhood Obesity (2010) Solving the Problem of Childhood Obesity Within a Generation: Report to the President. Washington, DC: TFCO; available at http:// www.letsmove.gov/tfco_fullreport_may2010.pdf

2. Food and Nutrition Service/US Department of Agriculture (2010) National School Lunch Program (NSLP) Quick Facts. Alexandria, VA: FNS/USDA; available at http:// www.fns.usda.gov/cga/FactSheets/NSLP_Quick_Facts.pdf

3. Food and Nutrition Service/US Department of Agriculture (2010) School Breakfast Program (SBP) Quick Facts. Alexandria, VA: FNS/USDA; available at http://www. fns.usda.gov/cga/FactSheets/SBP_Quick_Facts.pdf

4. Stallings VA, Suitor CW \& Taylor CL (editors) (2009) School Meals: Building Blocks for Healthy Children. Washington, DC: IOM/The National Academies Press.

5. Ralston K, Newman C, Clauson A et al. (2008) The National School Lunch Program: Background, Trends, and Issues. Report no. 61. Washington, DC: USDA/ERS; available at http://www.ers.usda.gov/Publications/ERR61/ERR61.pdf

6. Food and Nutrition Service/US Department of Agriculture (2000) Menu Planning in the National School Lunch Program. Alexandria, VA: FNS/USDA; available at http:// www.fns.usda.gov/cnd/menu/menu_planning.doc

7. Texas Education Agency (2009) Enrollment in Texas Public Schools, 2007-08. Document no. GE09 601 06. Austin, TX: Texas Education Agency.

8. Baxter SD, Thompson WO, Davis HC et al. (1997) Impact of gender, ethnicity, meal component, and time interval between eating and reporting on accuracy of fourth-graders self-reports of school lunch. J Am Diet Assoc 97, 1293-1298.

9. Domel SB, Baranowski T, Leonard SB et al. (1994) Accuracy of fourth and fifth grade students' food diaries compared to school lunch observation. Am J Clin Nutr 59 , Suppl. 1, S218-S220.

10. Cullen KW, Himes JH, Baranowski T et al. (2004) Validity and reliability of a behavior-based food coding system for measuring fruit, $100 \%$ fruit juice, vegetable, and sweetened beverage consumption: results from the Girls Health Enrichment Multisite Studies. Prev Med 38, Suppl., S24-S33.

11. Texas Department of Agriculture/Food and Nutrition Division (2004) Texas Public School Nutrition Policy. Austin, TX: TDA/ FND; available at http://www.squaremeals.org/

12. Domel SB, Baranowski T, Davis H et al. (1993) Measuring fruit and vegetable preferences among fourth and fifth grade students. Prev Med 22, 866-879.

13. Gordon A, Fox MK, Clark M et al. (2007) School Nutrition Dietary Assessment Study - III: Volume II: Student Participation and Dietary Intakes. Washington, DC: USDA/FNS; available at http://www.fns.usda.gov/ora/MENU/Published/ CNP/FILES/SNDAIII-Vol2.pdf \#xml=http://65.216.150.153/ texis/search/pdfhi.txt?query $=$ School + Nutrition + Dietary + Assessment + Study\&pr $=$ FNS\&prox $=$ page\&rorder $=500 \&$ rprox $=500 \&$ rdfreq $=500 \&$ rwfreq $=500 \&$ rlead $=500 \&$ rdepth $=$ $0 \&$ sufs $=0$ \&order $=r \& c q=\& i d=49 \mathrm{a} 5 \mathrm{~b} 27011$

14. Dillon MS \& Lane HW (1989) Evaluation of the offer vs. serve option within self-serve, choice menu lunch program at the elementary school level. J Am Diet Assoc 89, 1780-1785.

15. Condon EM, Crepinsek MK \& Fox MK (2009) School meals: types of foods offered to and consumed by children at lunch and breakfast. J Am Diet Assoc 109, Suppl. 2, S67-S78.

16. Fox MK, Gordon A, Nogales R et al. (2009) Availability and consumption of competitive foods in US public schools. J Am Diet Assoc 109, Suppl. 2, S57-S66.
17. Baxter SD \& Thompson WO (2002) Fourth-grade children's consumption of fruit and vegetable items available as part of school lunches is closely related to preferences. J Nutr Educ Behav 34, 166-171.

18. Burgess-Champoux T, Marquart L, Vickers Z et al. (2006) Perceptions of children, parents, and teachers regarding whole-grain foods, and implications for a school-based intervention. J Nutr Educ Behav 38, 230-237.

19. Sadeghi L \& Marquart L (2009) Whole grain snack intake in an after-school snack program: a pilot study. J Foodserv 20, 71-80.

20. Chan HW, Burgess-Champoux T, Reicks M et al. (2008) White whole-wheat flour can be partially substituted for refined-wheat flour in pizza crust in school meals without affecting consumption. J Child Nutr Mgt 32; available at http://docs.schoolnutrition.org/newsroom/jcnm/08spring/ chan/index.asp

21. Institute of Medicine/The National Academy Press (2010) Strategies to Reduce Sodium Intake in the United States. Washington, DC: IOM/The National Academies Press.

22. Gordon A, Crepinsek MK, Nogales R et al. (2007) School Nutrition Dietary Assessment Study III: Volume I: School Foodservice, School Food Environment, and Meals Offered and Served. Report no. CN-07-SNDA-III. Washington, DC: USDA/FNS; available at http://www.fns.usda.gov/ora/ MENU/Published/CNP/FILES/SNDAIII-Vol1.pdf\#xml=http:// 65.216.150.153/texis/search/pdfhi.txt?query $=$ School+Nutrition + Dietary + Assessment + Study\&pr $=$ FNS\&prox $=$ page\&rorder $=$ $500 \&$ rprox $=500 \&$ rdfreq $=500 \&$ rwfreq $=500 \&$ rlead $=500 \&$ rdepth $=0 \&$ sufs $=0 \&$ order $=r \& c q=\& i d=49 a 5 b 27011$

23. Pfaffman C, Bartoshuk LM \& McBurney DH (1971) Taste psychophysics. In Handbook of Sensory Physiology, Chemical Senses 2, Taste, pp. 75-101 [LM Beidler, editor]. New York, NY: Springer-Verlag.

24. Martin CK, Thomson JL, LeBlanc MM et al. (2010) Children in school cafeterias select foods containing more saturated fat and energy than the Institute of Medicine recommendations. J Nutr 9, 1653-1660.

25. Suarez-Balcazar Y, Redmond L, Kouba J et al. (2007) Introducing systems change in the schools: the case of school luncheons and vending machines. Am J Community Psychol 39, 335-345.

26. Fulkerson JA, French SA, Story M et al. (2004) Promotions to increase lower-fat food choices among students in secondary schools: description and outcomes of TACOS (Trying Alternative Cafeteria Options in Schools). Public Health Nutr 7, 665-674.

27. Snyder P, Anliker J, Cunningham-Sabo L et al. (1999) The Pathways study: a model for lowering the fat in school meals. Am J Clin Nutr 69, Suppl. 4, 810S-815S.

28. Wechsler H, Basch CE, Zybert P et al. (1998) Promoting the selection of low-fat milk in elementary school cafeterias in an inner-city Latino community: evaluation of an intervention. Am J Public Health 88, 427-433.

29. Hendy HM (1999) Comparison of five teacher actions to encourage children's new food acceptance. J Behav Med 21, 20-26.

30. Perry CL, Bishop DB, Taylor GL et al. (2004) A randomized school trial of environmental strategies to encourage fruit and vegetable consumption among children. Health Educ Behav 31, 65-76.

31. Schwartz MB (2007) The influence of a verbal prompt on school lunch fruit consumption: a pilot study. Int J Behav Nutr Phys Act 4, 6.

32. Livingstone MB, Robson PJ \& Wallace JM (2004) Issues in dietary intake assessment of children and adolescents. Br J Nutr 92, Suppl. 2, S213-S222. 